Rev. Med. Virol. 2011; 21: 181-200.

Published online in Wiley Online Library

(wileyonlinelibrary.com)

DOI: $10.1002 / \mathrm{rmv} .688$

R E U I E UJ

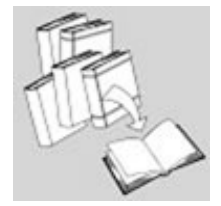

\title{
Viruses as key regulators of angiogenesis
}

\author{
Kristof Vrancken, Peter Vervaeke, Jan Balzarini and Sandra Liekens*
}

Rega Institute for Medical Research, Leuven, Belgium

\section{SUMMARY}

Angiogenesis is an important physiological process that is controlled by a precise balance of growth and inhibitory factors in healthy tissues. However, environmental and genetic factors may disturb this delicate balance, resulting in the development of angiogenic diseases, tumour growth and metastasis. During the past decades, extensive research has led to the identification and characterization of genes, proteins and signalling pathways that are involved in neovascularization. Moreover, increasing evidence indicates that viruses may also regulate angiogenesis either directly, by (i) producing viral chemokines, growth factors and/or receptors or (ii) activating blood vessels as a consequence of endothelial cell tropism, or indirectly, by (iii) modulating the activity of cellular proteins and/or (iv) inducing a local or systemic inflammatory response, thereby creating an angiogenic microenvironment. As such, viruses may modulate several signal transduction pathways involved in angiogenesis leading to changes in endothelial cell proliferation, migration, adhesion, vascular permeability and/or protease production. Here, we will review different mechanisms that may be applied by viruses to deregulate the angiogenic balance in healthy tissues and/or increase the angiogenic potential of tumours. Copyright (c) 2011 John Wiley \& Sons, Ltd.

Received: 23 December 2010; Revised: 1 March 2011; Accepted: 4 March 2011

\section{ANGIOGENESIS}

Angiogenesis involves the formation of new blood vessels from pre-existing vessels. In adults,

*Corresponding author: Prof. S. Liekens, Rega Institute for Medical Research, Minderbroedersstraat 10, blok x-bus 1030, B-3000 Leuven, Belgium.

E-mail: sandra.liekens@rega.kuleuven.be

\section{Abbreviations used:}

Ang-2, angiopoietin-2; AP, activator protein; ATLL, adult T-cell leukaemia; BM, basement membrane; CCL2, monocyte chemoattractant protein-1 (MCP-1); CM, conditioned medium; COX-2, cyclooxygenase-2; CXCL1, growth regulated oncogene- $\alpha(G R O-\alpha)$; CXCL4, platelet factor-4 (PF-4); CXCL8, interleukin-8 (IL-8); CXCL12, stromal cell-derived factor-1 (SDF-1); EBNA, EBV nuclear antigen; EC, endothelial cell; ECM, extracellular matrix; EGFR, epidermal growth factor receptor; FGF2, basic fibroblast growth factor; FGFR, fibroblast growth factor receptor; HCC, hepatocellular carcinoma; HIF, hypoxia-inducible factor; HPV, human papilloma virus; HSPG, heparan sulphate-containing proteoglycan; KS, Kaposi's sarcoma; KSHV, Kaposi's sarcoma-associated herpesvirus; LMP, latent membrane protein; $M A P K$, mitogen-activated protein kinase; MMP, matrix metalloproteinase; MT, membrane-type; NF-кB, nuclear factor-kB; NHL, non-Hodgkin's lymphoma; NPC, nasopharyngeal carcinoma; PlGF, placenta growth factor; PDGF, platelet-derived growth factor; PI3K, phosphoinositide 3-kinase; pVHL, von HippelLindau protein; STAT, signal transducer and activator of transcription; TP, thymidine phosphorylase; TIMP, tissue inhibitor of metalloproteinase; TVS, transplant vascular sclerosis; VE, vascular endothelial; VEGF, vascular endothelial growth factor; VEGFR, vascular endothelial growth factor receptor; vFLIP, viral FLICEinhibitory protein; $v G P C R$, viral G protein-coupled receptor; vIL-6, viral interleukin-6; vIRF, viral interferon regulatory factor. neovascularization is limited to wound healing and the female reproductive cycle. Under these physiological conditions, angiogenesis is well-regulated and only switched on for a short period of time. Unregulated angiogenesis may lead to many deadly and debilitating conditions, including cancer, skin diseases, blindness and cardiovascular disease [1].

Blood vessels consist of a layer of endothelial cells (ECs) surrounded by pericytes, which stabilize the vessels and provide survival signals. The first step in the angiogenesis cascade is the release of pro-angiogenic factors in response to hypoxia or nutrient deprivation [2]. Hypoxia-inducible factor-1 (HIF-1) is the principal regulator of angiogenesis. This transcription factor is composed of an oxygensensitive $\alpha$ subunit and a constitutively expressed $\beta$ subunit. Under normoxic conditions, the $\alpha$ subunit is rapidly degraded via a proteasomedegradation pathway (Figure 1). In contrast, under hypoxia, the $\alpha$ subunit is able to accumulate and form a heterodimer with the $\beta$ subunit. This active transcription factor binds to hypoxia-response elements in the promoter of various genes, whose products are involved in angiogenesis [3]. Next, pro-angiogenic factors [e.g. vascular endothelial growth factor (VEGF), angiopoietins (Ang)] activate the ECs by binding to specific EC receptors 


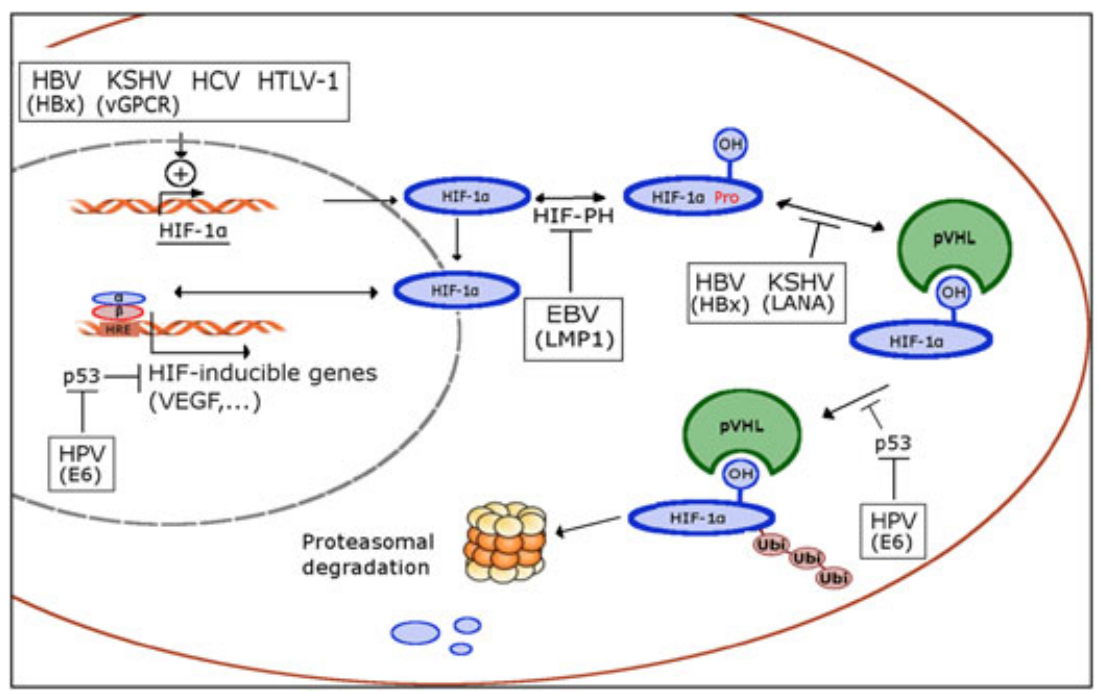

Figure 1. Viral regulation of HIF-1 activity. Hypoxia-inducible factor-1 (HIF-1), the principal regulator of both physiological and pathological angiogenesis, is composed of an oxygen-sensitive $\alpha$ subunit and a constitutively expressed $\boldsymbol{\beta}$ subunit. Under normal oxygen conditions, HIF-1 $\alpha$ (blue) is rapidly hydroxylated by prolyl hydroxylases (HIF-PH), which enable the binding of HIF-1 $\alpha$ to the von Hippel-Lindau protein (pVHL, green), a recognition component of the E3 ligase complex. This binding promotes the ubiquitination of HIF-1 $\alpha$, thereby targeting it for proteasomal degradation. Because prolyl hydroxylases require molecular oxygen for their enzymatic activity, hypoxic conditions inhibit proline hydroxylation of HIF-1 $\alpha$, resulting in HIF-1 $\alpha$ accumulation and its dimerization with HIF-1 $\beta$. The heterodimeric transcription factor binds to hypoxia-response elements (HREs) within the promoter of target genes and activates the expression of a wide variety of genes involved in angiogenesis (e.g. VEGF) (reviewed in [3]). Viruses can interfere with this pathway by increasing HIF-1 $\alpha$ transcription and/or protein stability. The viral oncoproteins vGPCR (expressed by KSHV) [65] and HBx (expressed by HBV) [92] up-regulate HIF-1 $\alpha$ expression by activating the MAPK pathway. HCV and HTLV-1 have also been shown to increase HIF-1 $\alpha$ transcription, although the viral proteins involved have not yet been elucidated $[105,166]$. HBV HBx stabilizes HIF-1 $\alpha$ in normoxia by inhibiting its interaction with pVHL [91], whereas KSHV LANA stimulates degradation of pVHL, thereby increasing the cellular pool of HIF-1 $\alpha$ [167]. HPV E6 may increase HIF-1 $\alpha$ levels by promoting the degradation of p53. This, in turn, may abolish p53-evoked transcriptional repression of HIF-1 and/or inhibit p53-induced ubiquitination of HIF-1 $\alpha$ [82]. On the other hand, EBV LMP1 up-regulates the E3 ubiquitin ligase, which induces degradation of prolyl hydroxylases that normally mark HIF-1 $\alpha$ for degradation [28]

(see further). As a consequence, the pericytes detach, and the 'activated' ECs produce proteolytic enzymes [e.g. matrix metalloproteinases (MMPs)] that degrade the basement membrane and extracellular matrix (ECM) surrounding the existing vessel [4]. This enables the ECs to migrate and proliferate in the perivascular space in the direction of the source of the angiogenic stimulus (e.g. tumour, hypoxic or inflamed tissue). The newly formed sprout synthesizes a new basement membrane, recruits pericytes and connects with another sprout to allow blood flow through the new capillary $[5,6]$. These different steps are regulated by a multitude of pro-angiogenic and anti-angiogenic proteins, including soluble factors, ECM components, adhesion molecules and cell-surface receptors (Figure 2).

Soluble factors with angiogenic activity can be largely divided into two groups. The first group consists of the VEGF family and the angiopoietins, which mainly activate ECs. VEGF, one of the most potent and best characterized angiogenic factors, stimulates EC proliferation and migration, MMP production as well as vascular permeability by activating high-affinity tyrosine kinase receptors VEGFR-1 (Flt1) and VEGFR-2 (KDR/Flk1) on the surface of ECs [7]. Angiopoietins (Ang-1 and Ang-2) are ligands of the endothelial-specific tyrosine kinase receptor Tie-2. The binding of Ang- 1 to Tie-2 results in receptor activation and the transduction of signals that promote blood vessel stabilization. In contrast, Ang-2, by inhibiting the interaction of Ang-1 with Tie-2, induces destabilization of the vessels, rendering them more responsive to angiogenic factors, such as VEGF [8].

The second class consists of growth factors, chemokines, cytokines and angiogenic enzymes that activate a broad range of cell types besides ECs. The prototype member of this group is basic fibroblast 


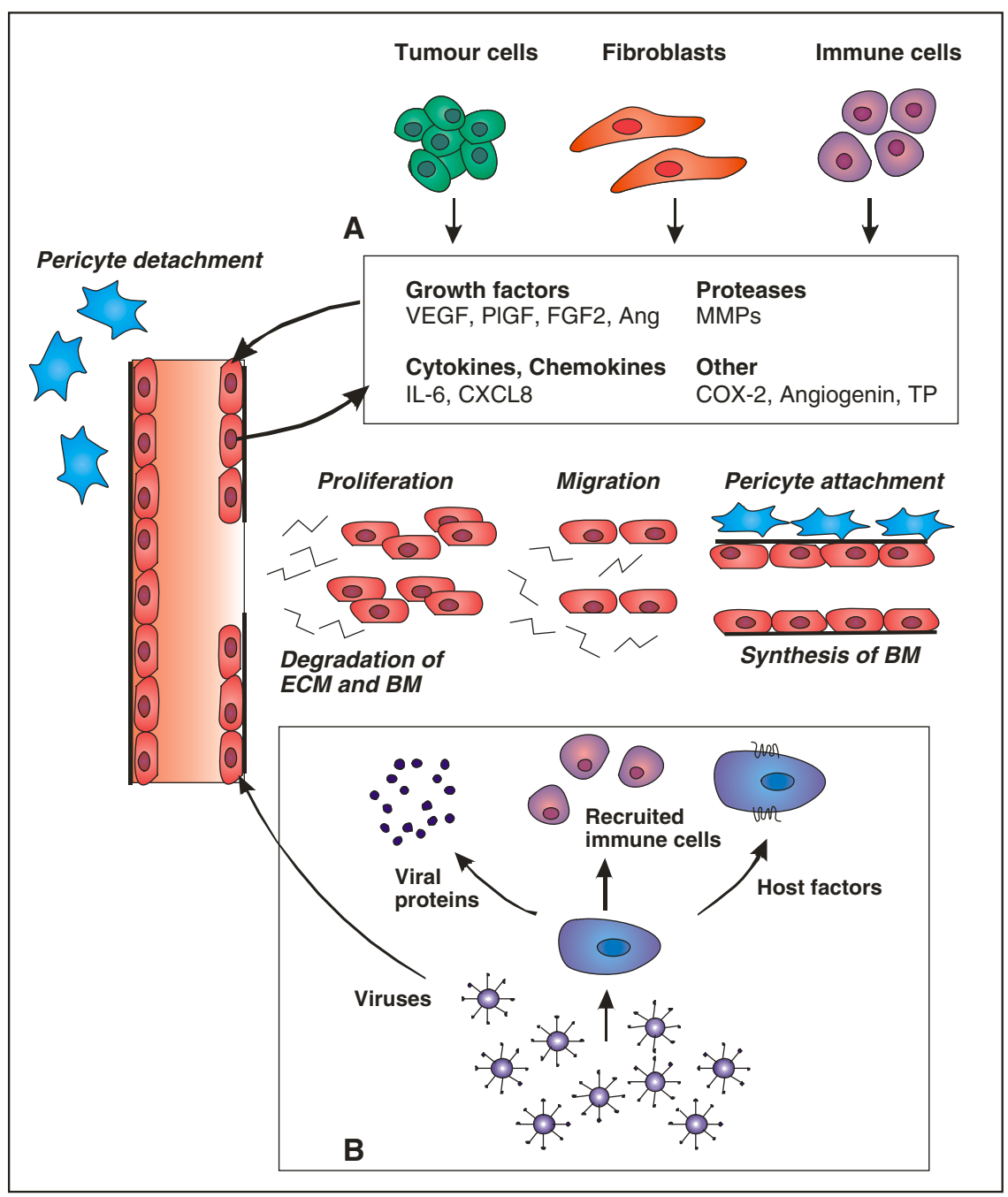

Figure 2. Regulation of angiogenesis by viruses. A. Angiogenesis is regulated by a wide variety of pro-angiogenic and anti-angiogenic molecules including growth factors, chemokines, angiogenic enzymes and ECM components. Growth factors, such as VEGF and Ang-2, activate the ECs by binding to specific EC receptors. MMPs degrade the basement membrane (BM) and remodel the ECM, allowing the ECs to migrate and proliferate. This requires the concerted action of soluble factors, ECM components and adhesion molecules. MMPs also increase the biological availability of ECM-sequestered growth factors. During the resolution phase, a new BM is formed, and pericytes are recruited to stabilize the newly formed vessel. Finally, pro-angiogenic factors are down-regulated, and/or anti-angiogenic proteins are produced to keep the endothelium in a quiescent state. During pathological angiogenesis, tumour cells and/or various stromal cell types (i.e., fibroblasts, macrophages and neutrophils) continue to secrete pro-angiogenic and pro-inflammatory factors, resulting in a failure to resolve the angiogenesis cascade. B. Viruses may apply direct and indirect mechanisms to deregulate the angiogenesis balance or contribute to tumour angiogenesis. (1) Viruses (e.g. KSHV, HCMV) may directly activate blood vessels as a consequence of endothelial cell tropism. (2) Viruses may produce viral proteins (e.g. HIV-Tat) with direct vascular-promoting activity. (3) Viral infection is often accompanied by acute or chronic inflammation. Inflammatory mediators and recruited immune cells may create an angiogenic microenvironment or act with pro-angiogenic factors to synergistically stimulate angiogenesis. (4) Viruses or viral proteins modulate intracellular signalling pathways that activate the expression of host factors with angiogenic activity

growth factor (FGF2). FGF2 induces EC proliferation, migration and protease production by binding to low-affinity heparan sulphate-containing proteoglycans (HSPG) and high-affinity tyrosine kinase fibroblast growth factor receptors (i.e. FGFR1 and
FGFR2) [9]. The interaction of FGF2 with HSPG promotes FGF2 oligomerization, which is required for the dimerization and subsequent activation of the FGFR. Chemokines are key players in the recruitment of immune cells at sites of infection and/or 
inflammation. As such, they may stimulate angiogenesis indirectly. Some chemokines [e.g. interleukin-8 (CXCL8), stromal cell-derived factor-1 (CXCL12)] also possess direct pro-angiogenic activity, whereas others [e.g. platelet factor-4 (CXCL4)] are angiostatic. They exert their action by binding to seven-transmembrane $G$ protein-coupled receptors [10]. Also, pro-inflammatory cytokines (e.g. TNF- $\alpha$, IL-1, IL-6) have been shown to stimulate angiogenesis. These cytokines mainly act in an indirect manner by up-regulating the expression of direct-acting angiogenic factors. As such, IL-6 enhances the proliferation, migration and tube formation of ECs in vitro by up-regulating the expression of FGF2, VEGF, VEGFR-2 and MMPs [11-13]. Enzymes with angiogenic activity include cyclooxygenase 2 (COX-2), angiogenin and thymidine phosphorylase (TP). COX-2 catalyses the production of chemical messengers, such as prostaglandins [14]. Some of these messengers are endowed with pro-inflammatory and/or proangiogenic activities. Angiogenin, a member of the ribonuclease superfamily, hydrolyzes cellular tRNAs resulting in decreased protein synthesis. However, the protein also binds to ECs and is transported to the nucleus from where it induces a wide variety of responses including EC proliferation, migration and invasion and protease activation [15]. TP catalyses the phosphorolysis of thymidine to thymine and $\alpha$-2-deoxy-D-ribose-1-phosphate, which is rapidly converted to 2-deoxy-D-ribose. The latter has been shown to induce EC migration in vitro and angiogenesis in vivo [16].

Angiogenesis is also regulated by adhesion molecules, such as integrins and cadherins. Integrins mediate the attachment of cells to ECM proteins. In particular, $\alpha_{\mathrm{v}} \beta_{3}$, which is a receptor for a number of proteins with an arginineglycine-aspartic acid (RGD) sequence (e.g. fibronectin, vitronectin, laminin) plays a key role during angiogenesis [17]. Vascular endothelial (VE)-cadherin determines the integrity of the endothelial layer [18]. Consequently, degradation of VE-cadherin induces EC apoptosis and vascular permeability.

The activity of these pro-angiogenic factors is counterbalanced by endogenous inhibitors of angiogenesis. These anti-angiogenic molecules assure a tight regulation of the angiogenesis cascade and serve to keep the ECs in a quiescent state when neovascularization is not needed. They include tissue inhibitors of MMPs (TIMPs), anti-angiogenic chemokines (e.g. CXCL4), thrombospondins (TSP) and various molecules that are derived from the ECM (e.g. angiostatin, endostatin) [4-6,10].

Accumulating data indicate that angiogenesis is not only regulated by hypoxia or cellular factors but also by various viruses, which either express their own pro-angiogenic factors or modulate the activity of cellular proteins (Figure 2). This review focuses on those human viruses for which a (clear) link with angiogenesis has been established (Table 1).

\section{HUMAN TUMOUR-INDUCING VIRUSES}

So far, at least six viruses have been associated with human cancer. These include the DNA viruses Epstein-Barr virus (EBV), Kaposi's sarcomaassociated herpesvirus (KSHV), human papilloma virus (HPV), HBV and the RNA viruses, $\mathrm{HCV}$ and human T-cell lymphotropic virus type 1 (HTLV-1). These viruses account for $10 \%-15 \%$ of the cancers worldwide [19].

\section{Epstein-Barr virus}

The herpesvirus family consists of large doublestranded DNA viruses, which are divided into three subfamilies: $\alpha$-herpesviruses, $\beta$-herpesviruses and $\gamma$-herpesviruses. After primary infection, these viruses usually establish life-long latency. In immunocompetent people, latent infection is typically asymptomatic. However, the $\gamma$-herpesviruses EBV and KSHV, which preferentially infect B lymphocytes, are associated with malignancies of lymphoid, epithelial, and endothelial origin [19].

\section{Epstein-Barr virus pathology}

Epstein-Barr virus was isolated more than 40 years ago from a B-cell lymphoma and was the first virus for which a direct association with human cancer was established. The virus induces multiple malignancies, including Burkitt's lymphoma, Hodgkin's lymphoma, nasopharyngeal carcinoma (NPC) and gastric carcinoma $[19,20]$. In EBV-induced malignancies, EBV infection is predominantly latent. During latency, only a subset of viral genes, that is, six EBV nuclear antigens (EBNAs) and three latent membrane proteins (LMPs) are expressed, which allows the virus to persist in the host without being recognized by the immune system. 


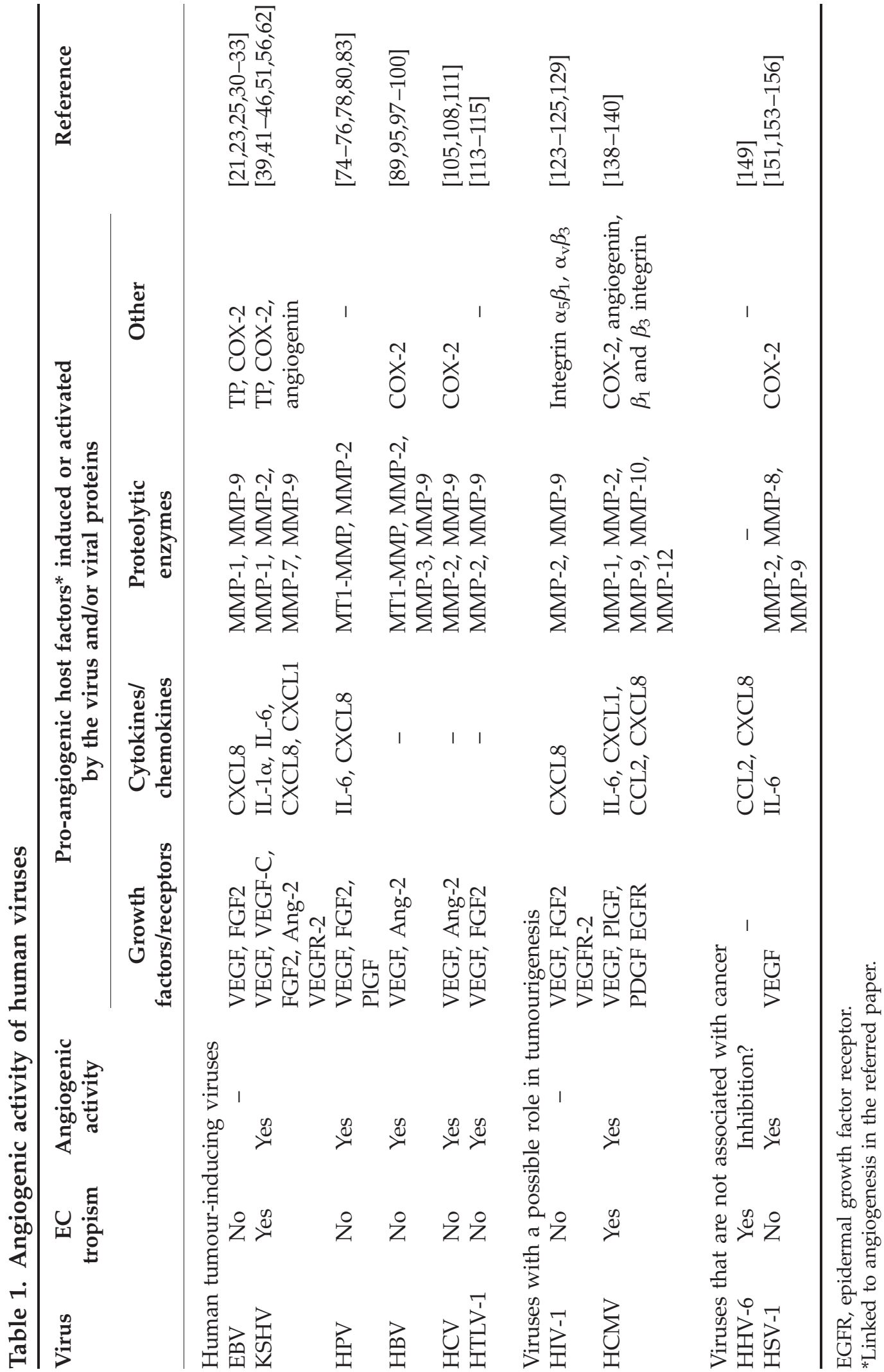

Copyright () 2011 John Wiley \& Sons, Ltd.

Rev. Med. Virol. 2011; 21: 181-200. 
Angiogenic activity of Epstein-Barr virus

The EBV LMP1 protein is detected in at least $70 \%$ of NPC lesions. Immunohistochemical analysis of NPC tissue samples demonstrated a significant correlation between LMP1 expression and angiogenesis, suggesting that LMP1 increases the production of angiogenic factors [21,22]. In particular, significant correlations have been established between LMP1 and COX-2 [23], MMP-9 [24], CXCL8 [21] and TP [25] levels in NPC. Angiogenesis not only promotes primary tumour growth, it also facilitates the dissemination of tumour cells into the blood and the development of distant metastases. As such, through the induction of angiogenesis, LMP1 may enhance lymph node metastasis of NPC [22]. Moreover, in non-Hodgkin's lymphoma (NHL), the expression of the viral
LMP1 protein was correlated with that of VEGF and with survival rate, suggesting an important role for VEGF in the pathogenesis of EBV-induced NHL [26].

In agreement with the clinical data, LMP1 was found to activate the expression of various proangiogenic proteins in vitro (Table 1). LMP1 is considered the principal oncoprotein of EBV [20]. It acts as a constitutively active receptor that mimics activated CD40, a member of the TNF receptor family [27]. As such, LMP1 activates several signalling pathways in a ligand-independent manner (Table 2). In particular, LMP1 increases the activity of HIF-1 $\alpha$ in EBV-negative NPC cells, resulting in enhanced expression of the major HIF-1 responsive gene VEGF [28,29]. Nuclear factor-kappaB (NF-kB) is involved in LMP-1-induced expression of FGF2 [30],

Table 2. Viral proteins with angiogenesis-modulating function

\begin{tabular}{|c|c|c|c|c|}
\hline Virus & $\begin{array}{l}\text { Angiogenic activity } \\
\text { involved in pathology }\end{array}$ & $\begin{array}{c}\text { Viral proteins } \\
\text { with potential } \\
\text { angiogenic activity }\end{array}$ & $\begin{array}{l}\text { Signalling } \\
\text { pathways involved }\end{array}$ & Reference \\
\hline \multirow[t]{2}{*}{ EBV } & Nasopharyngeal carcinoma & LMP1 & $\begin{array}{l}\text { HIF-1 } \alpha, \text { MAPK, } \\
\text { NF-кB, JAK/STAT }\end{array}$ & {$[25,28,163]$} \\
\hline & Burkitt's lymphoma & EBNA1 & $\begin{array}{l}\text { MAPK, HIF-1 } \alpha, \\
\text { STAT-1 }\end{array}$ & {$[34,164]$} \\
\hline \multirow[t]{8}{*}{ KSHV } & Kaposi's sarcoma & LANA & MAPK, HIF-1 $\alpha$ & {$[50,165]$} \\
\hline & & vCCL1, 2, 3 & ND & {$[54,55]$} \\
\hline & & vGPCR & $\begin{array}{l}\text { VEGFR-2, HIF-1 } \alpha, \\
\text { JAK/STAT, MAPK, } \\
\text { NF-кB, PI3K/Akt }\end{array}$ & {$[62-67]$} \\
\hline & & vIL-6 & MAPK & [58] \\
\hline & & vFLIP & MAPK, NF-кB & [51] \\
\hline & & vIRF3 & HIF-1 $\alpha$ & [59] \\
\hline & & K1 & PI3K/Akt & {$[36,60]$} \\
\hline & & miRNA & - & [52] \\
\hline \multirow[t]{3}{*}{ HPV } & Cervical carcinoma & E5 & MAPK, PI3K & [79] \\
\hline & & E6 & $\mathrm{HIF}-1 \alpha$ & [80] \\
\hline & & E7 & $\mathrm{HIF}-1 \alpha$ & [80] \\
\hline $\mathrm{HBV}$ & Hepatocellular carcinoma & $\mathrm{HBx}$ & HIF-1 $\alpha$, MAPK & {$[91,92]$} \\
\hline $\mathrm{HCV}$ & Hepatocellular carcinoma & Core? NS5A? E2? & - & {$[110,111]$} \\
\hline HTLV-1 & Adult T-cell leukaemia & Tax? & - & [115] \\
\hline HIV-1 & AIDS-Kaposi's sarcoma & Tat & $\begin{array}{l}\text { VEGFR-2, integrins, } \\
\text { MAPK }\end{array}$ & {$[121,123,125,127]$} \\
\hline HCMV & Transplant vascular sclerosis & US28 & NF-кB & {$[135,143]$} \\
\hline HHV-6 & - & Anti-angiogenic U94 & - & [148] \\
\hline HSV-1 & Herpetic stromal keratitis & - & - & [151] \\
\hline
\end{tabular}


CXCL8 [21] and TP [25]. Moreover, LMP1 stimulates the expression and activity of several matrix metalloproteinases in transfected, EBV-negative, NPC cells [31,32]. Transgenic mice that express LMP1 in the epithelial cells display increased levels of MMP-9 with increasing vascularization in the skin, indicating that MMPs are, at least in part, responsible for the angiogenic activity of LMP1 [33].

Like LMP1, the viral EBNA1 protein is expressed in all EBV-associated tumours. EBNA1 activates the transcription factor AP-1 in epithelial cells, resulting in increased expression of AP-1 target genes, including HIF-1 $\alpha, V E G F$ and CXCL8. Consequently, conditioned medium (CM) from EBNA1-expressing cells enhances angiogenesis in vitro [34].

Thus, although a direct angiogenic activity of EBV has not yet been reported and EBV does not infect ECs, the virus, and in particular its latent oncoprotein LMP1, induces the expression of various cellular factors that may stimulate angiogenesis in a paracrine way (reviewed in [35]) (Table 1). Moreover, the angiogenic activity of LMP1 has been directly correlated with aggressiveness (i.e. increased metastasis and/or shorter patient survival) of NPC and NHL in clinical samples [22,26].

\section{Kaposi's sarcoma-associated herpesvirus}

Kaposi's sarcoma-associated herpesvirus pathology Kaposi's sarcoma-associated herpesvirus is the etiologic agent of Kaposi's sarcoma (KS) and two rare forms of B-cell lymphoproliferative diseases: primary effusion lymphoma and multicentric Castleman's disease $[19,36]$. KS is grouped into four epidemiological forms: classic KS, appearing sporadically in elderly men of the Mediterranean area; endemic KS, which exists in subequatorial Africa; iatrogenic KS, occurring in immunosuppressed persons after organ transplantation; and AIDS-associated KS (reviewed in [36]). Whereas classic KS is a mild disease that is limited to the skin, AIDS-associated KS presents as a highly aggressive tumour that often disseminates to the liver, spleen, gastrointestinal tract and lungs.

KS is a strongly vascularized tumour, characterized by proliferating spindle cells (the KS tumour cells, which are considered to originate from ECs), inflammatory cells and abnormal, leaky, slit-like blood vessels. KSHV is present in the majority of the spindle cells of the lesion, but only few cells (1-5\%) express KSHV lytic proteins [37]. However, these lytic cells are essential for KS development, suggesting an interplay between latent and lytic proteins in establishing KS [38].

Angiogenic activity of Kaposi's sarcoma-associated herpesvirus Infection of ECs with KSHV induces the transcription of several host genes involved in neovascularization $[39,40]$. As a consequence, KSHV-infected ECs show increased adhesion, invasion, survival and angiogenesis. KSHV-induced angiogenesis is mediated by various cellular factors, including VEGF [41], VEGF-C (a member of the VEGF family that stimulates lymphangiogenesis) [41], angiogenin [42], Ang-2 [43], COX-2 [44] and several chemokines [45] and proteolytic enzymes (Table 1) [46]. KS lesions, as well as ECs that are latently infected with $\mathrm{KSHV}$, contain increased levels of HIF- $1 \alpha$ and HIF- $2 \alpha$, due to transcriptional activation by KSHV [47]. Thus, increased HIF activity under normoxia may partly account for the up-regulation of angiogenic genes in ECs after KSHV infection. Infection of ECs with KSHV also induces vascular permeability by degradation of the cell-cell adhesion molecule VE-cadherin [48]. Increased vascular permeability may facilitate virus spread and promote inflammation and angiogenesis, thus contributing to KS progression.

\section{Kaposi's sarcoma-associated herpesvirus genes involved in angiogenesis}

Kaposi's sarcoma-associated herpesvirus encodes at least 89 open reading frames, many of which are unique among the Herpesviridae and are homologues of cellular proteins involved in cell cycle control, apoptosis prevention and immune regulation. Moreover, several KSHV-encoded proteins possess angiogenic and/or oncogenic activity (reviewed in $[19,35]$ and Table 2).

During the latent cycle, only a few KSHV-encoded genes are expressed, including LANA, vCyclin, vFlip, Kaposin $B$ and a microRNA cluster [19]. Present data indicate that these proteins confer a growth advantage to the infected cells, rendering them more responsive to the paracrine effects of KSHV lytic proteins $[19,49]$. An additional role of these latency proteins may be to induce angiogenesis. Latencyassociated nuclear antigen (LANA) was found to inhibit the degradation of HIF- $1 \alpha$ and to stimulate angiogenesis in vitro [42,50]. Viral FLICE-inhibitory 
protein (vFLIP) increases the expression of various pro-angiogenic proteins (e.g. IL-6, TP, COX-2...) in ECs, possibly via activation of NF- $\mathrm{B}$ [51]. Moreover, miRNAs of KSHV may stimulate angiogenesis by inhibiting the expression of the anti-angiogenic protein TSP-1 [52]. One of the most up-regulated miRNAs in KSHV-infected ECs and in KS lesions is miR-132, which induces EC proliferation and the formation of tube-like structures in vitro [53].

Kaposi's sarcoma-associated herpesvirus lytic proteins that contribute to the angiogenic phenotype of KS include, among others, virally encoded chemokines, viral interferon regulatory factors (vIRFs), vIL-6 and the viral G protein-coupled receptor (vGPCR) (Table 2) [35]. The virally encoded chemokines (vCCL1, vCCL2 and vCCL3) display potent angiogenic activity in the chicken chorioallantoic membrane assay [54,55]. Moreover, lentiviral gene delivery of vCCL2 to ECs stimulated angiogenesis in subcutaneously implanted matrigel plugs in mice. vCCL2 was also shown to up-regulate the expression of various proangiogenic factors (e.g. VEGF, IL-1 $\alpha$ ) [56]. vIL-6 stimulates tumour growth by increasing vascularization and VEGF production [57]. vIL-6 was also shown to up-regulate Ang-2 and VEGF-C in lymphatic endothelial cells (LECs) [58]. Several other lytic proteins, including vIRF3 and K1, stimulate angiogenesis by inducing VEGF and/or MMP expression $[41,59,60]$. These viral proteins are expressed during lytic infection, indicating that they act in a paracrine manner to stimulate latently infected KS cells, ECs and/or inflammatory cells in the tumour microenvironment.

Viral G protein-coupled receptor, a constitutively active chemokine receptor, is considered the major oncoprotein of KSHV [61]. vGPCR immortalizes ECs by constitutive expression and activation of VEGF receptor-2 (VEGFR-2) [62]. KS biopsies from patients with AIDS as well as animal models of KS indicate a key role for protein kinase B/Akt in vGPCR-induced angiogenesis and development of KS $[63,64]$. However, expression of vGPCR in EC also leads to the activation of several other intracellular signalling pathways [e.g. HIF-1 $\alpha$, mitogen-activated protein kinases (MAPKs), signal transducer and activator of transcription (STAT) and NF-kB] (Table 2), which, in turn, induce the expression of various pro-inflammatory cytokines (e.g. IL-6) and pro-angiogenic chemokines (e.g. CXCL8), growth factors (e.g. VEGF, VEGF-C) and proteolytic enzymes (e.g. tissue and urokinase type plasminogen activator) [65-68] (Table 1). Thus, vGPCR signalling may affect every step in the angiogenesis cascade, implying a key role for this lytic protein in KS pathogenesis. Interestingly, vGPCR expression could not be demonstrated in classic KS. In contrast, in AIDS-KS tissues, vGPCR was readily detected together with HIV-Tat protein, suggesting that HIV-Tat may induce vGPCR expression, leading to a more aggressive phenotype (see further) [69].

\section{Human papillomavirus}

Human papillomaviruses are double-stranded DNA viruses that cause a wide range of hyperproliferative diseases. Furthermore, persistent infection with high-risk HPV types (e.g. HPV16 or HPV18) causes the development of anogenital cancers, which are characterized by deregulated, high-level expression of the HPV early genes E6 and E7 (reviewed in [70]).

Human papillomavirus infection is associated with increased angiogenesis, both in high-risk HPVassociated cervical dysplasia and cancer and in the more benign HPV-associated warts [71-73]. Although HPV mainly infects epithelial cells, the virus may stimulate neovascularization indirectly by increasing the secretion of angiogenic proteins, which can activate ECs in a paracrine manner (Table 1). As such, VEGF expression and secretion were found to be significantly increased in HPV16positive cells as compared with HPV-negative cells [74]. Other pro-angiogenic molecules, such as FGF2, CXCL8 and placenta growth factor (PIGF), a VEGF family member, were also up-regulated in HPV16positive cells, while the expression of the antiangiogenic TSP-1 and TSP-2 was down-regulated $[75,76]$. Consequently, CM of HPV16-positive cells or E6/E7-expressing keratinocytes stimulated EC proliferation and migration in vitro and angiogenesis in matrigel plugs implanted in mice $[75,77]$. This supports the hypothesis that these proteins not only contribute to uncontrolled growth of keratinocytes but also to neovascularization required for tumour growth.

High VEGF levels were initially associated with the presence of the E6 viral oncoprotein, but subsequent experiments indicated that E5 and E7 proteins are also implicated in VEGF up-regulation $[74,78,79]$. VEGF expression induced by E6 and E7 was found to be HIF-1 $\alpha$ dependent (Table 2) [80]. 
Both HIF-1 $\alpha$ activity and TSP levels are regulated by $\mathrm{p} 53$, which is inactivated by E6, suggesting that the angiogenic activity of E6 is mediated by p53 inactivation $[75,81,82]$. HPV infection may further stimulate neovascularization by increasing the activity of proteolytic enzymes; that is, E7 proteins of the high-risk HPV types induce membrane-type (MT)-1 MMP expression, which in turn activates MMP-2 [83].

Besides these indirect effects of HPV on angiogenesis, some data indicate that HPV may also directly affect ECs. In vitro, human cervical carcinoma cells expressing HPV16 E7 release the viral protein into the extracellular compartment [84]. Moreover, recombinant E7 has been shown to enter cervical microvascular ECs and to increase the production of the angiogenic cytokines IL-6 and CXCL8 after prolonged incubation [85]. This effect was not observed when macrovascular ECs were incubated with HPV16 E7, suggesting selectivity of the E7 oncoprotein for capillary endothelium. However, more research is needed to unravel the in vivo relevance of these findings. Finally, HPV, generally regarded as a strict epitheliotropic pathogen, has been detected at both DNA and protein levels in ECs of blood capillaries adjacent to oral and cervical cancers [86]. While it seems unlikely that HPV can replicate in ECs, the mechanism by which it is taken up and the possible impact this might have on ECs and on angiogenesis are certainly worth further investigation.

\section{Hepatitis B virus and hepatitis $C$ virus}

An estimated 500 million people worldwide are chronically infected with HBV or HCV. Chronic HBV and $\mathrm{HCV}$ infections and associated liver cirrhosis represent major risk factors for hepatocellular carcinoma (HCC), being implicated in more than $70 \%$ of HCC cases (reviewed in [87]). Although the relationship between HCC and persistent HBV or HCV infection has been well documented, an understanding of their exact role in HCC formation is difficult to establish as hepatocarcinogenesis is a multi-factorial process that may require decades [87]. Recent data indicate that virus-induced stimulation of angiogenesis may contribute to the pathogenesis of HCC, which is a highly vascularized tumour (see below and [88]).

\section{Hepatitis B virus}

Hepatitis B virus is a small DNA virus of the Hepadnaviridae family that does not express a typical oncogene. However, insertional activation of cellular proto-oncogenes by integration of HBV DNA, longterm immune-mediated effects and the regulatory protein $\mathrm{HBx}$ may contribute to $\mathrm{HBV}$-induced hepatocarcinogenesis. In addition, $\mathrm{HBx}$ has been shown to possess pro-angiogenic activity. When mice were injected subcutaneously with matrigel containing either hepatoma cells transfected with $\mathrm{HBx}$ or with an empty vector, significantly more blood vessels were observed in the matrigel containing HBx transfectants. Moreover, VEGF expression was shown to be increased in HBx-expressing hepatoma cells both under hypoxic and normoxic conditions [89]. VEGF expression was also upregulated in the liver of HBx transgenic mice [90]. HBx stimulates angiogenesis through transcriptional activation and stabilization of HIF-1 $\alpha$ [91,92], which in turn activates VEGF transcription (Table 2). Upregulation of VEGF and HIF-1 $\alpha$ by HBV might play an important role in the clinical setting because patient studies have shown that VEGF contributes to angiogenesis in all stages of HCC [93] and that increased HIF-1 $\alpha$ levels in HCC samples are correlated with poor prognosis [94]. HBx protein also stimulates the expression and secretion of Ang-2 in liver tissue [95]. Because VEGF and Ang-2 expression are positively correlated with microvessel density in HBV-induced HCC [96], it seems likely that stimulation of both angiogenic factors by $\mathrm{HBx}$ contributes to HBV-associated HCC. Finally, HBx may contribute to HCC angiogenesis by increasing the production of MMPs [97-100] and COX-2 [97].

Thus, although HBV does not infect ECs, angiogenic factors produced by HBV-infected hepatocytes may stimulate liver angiogenesis in a paracrine way (Table 1). Indeed, CM of HBV-infected hepatocytes was shown to induce tube formation of ECs in vitro [101].

\section{Hepatitis C virus}

Hepatitis $C$ virus is a positive strand RNA virus belonging to the Flaviviridae. In contrast to HBV, $\mathrm{HCV}$ is unable to integrate into the host genome, which suggests that inflammatory and/or angiogenic events and viral protein expression are more important in $\mathrm{HCV}$-induced hepatocarcinogenesis.

Chronic hepatitis C patients were shown to contain high levels of angiogenesis markers, such as VEGF, Ang-2 and soluble Tie-2 in the serum, which were significantly reduced by antiviral therapy [102]. Moreover, the number of newly formed 
blood vessels was directly related to fibrosis stage in liver biopsies of these patients [103]. Interestingly, HCC tissue samples from $\mathrm{HCV}$-infected patients were shown to be even more vascularized than HBV-associated HCC [104].

Experimental studies showed that $\mathrm{CM}$ from HCV-infected Huh7 hepatoma cells is more angiogenic than CM of uninfected Huh7 cells in the chicken chorioallantoic membrane assay [105]. Moreover, HCV gene expression stabilizes HIF-1 $\alpha$ under normoxic conditions. This finding could be confirmed in Huh7 cells expressing the HCV subgenomic replicon, indicating that HIF-1 $\alpha$ stabilization is mediated by (a subset of) HCV nonstructural genes [105]. Consequently, expression and secretion of VEGF, a HIF-1 $\alpha$ target, by Huh7 cells was markedly increased after $\mathrm{HCV}$ infection (Table 1) [105]. HCV-induced reactive oxygen species were shown to stabilize HIF-1 $\alpha$ by activation of MAPK, PI3K, STAT-3 and NF-кB signal transduction pathways $[105,106]$. While these authors showed that the non-structural proteins were sufficient for the increase in VEGF expression, also core-expressing Huh7 cells were found to stimulate VEGF expression and secretion [107].

Furthermore, HCV induces the expression of Ang-2 [108]. Also, MMP-2 could be up-regulated by the presence of the HCV core protein [109] or by binding of the HCV envelope protein E2 to the CD81 receptor present on hepatic stellate cells [110]. Finally, COX-2 expression and activity were induced in coreexpressing or NS5A-expressing hepatocytes, whereas core, but not NS5A, exerted a stimulatory effect on MMP-9 levels [111]. These findings were supported by clinical studies, which showed that patients with $\mathrm{HCV}$ chronic liver disease (seronegative for HBV) have an increased intrahepatic content of COX-2, MMP-2 and MMP-9 [111], which, along with VEGF and Ang-2, could play an important role in $\mathrm{HCV}$-induced angiogenesis in HCC.

Finally, it should be noted that inflammatory mediators as well as immune cells that are recruited to the inflamed liver tissue may play a significant part in the stimulation of angiogenesis by $\mathrm{HBV}$ or $\mathrm{HCV}$ infection (Figure 2) [87].

\section{Human T-cell lymphotropic virus type 1}

Human T-cell lymphotropic virus type 1 is the etiological agent of adult T-cell leukaemia (ATLL), an aggressive malignancy of activated T cells characterized by frequent visceral invasion of tumour cells (reviewed in [112]). The invasive nature of HTLV-1-associated disease suggests a close interaction between HTLV-1-infected cells and ECs. In vitro, HTLV-1-transformed cells induce the production of MMP-2 and MMP-9 by ECs and the down-regulation of TIMPs [113]. Moreover, $\mathrm{CD}^{+}{ }^{+}$T-cell lines constitutively expressing HTLV-1 secrete higher levels of VEGF and FGF2 and are more angiogenic than HTLV-1 negative cells [114,115]. Accordingly, plasma samples from ATLL patients showed very high levels of VEGF and FGF2 [113]. Reducing the HTLV-1 proviral load resulted in decreased VEGF plasma levels in ATLL patients [116]. Furthermore, an increased microvessel density was observed in several organs from ATLL patients as compared with normal organs from matched controls, suggesting that angiogenesis plays an important role in ATLL progression [117].

Few data are available on the underlying molecular mechanisms behind these findings. The viral transcriptional activator protein Tax was proposed to be sufficient for VEGF up-regulation [115], but these findings were later contradicted [118]. Thus, more research is needed to identify the viral factors implicated in angiogenesis stimulation by HTLV-1.

\section{VIRUSES WITH A POSSIBLE ROLE IN TUMOURIGENESIS}

\section{Human immunodeficiency virus}

Several clinical features of AIDS cannot be solely explained by infection of $\mathrm{CD}^{+}$cells by HIV-1. In particular, KS is the most common malignancy in HIV-1-infected, untreated individuals. KS is associated with KSHV infection (see above), but HIV-1 may act as a co-factor in KS pathology (reviewed in [36]). Early studies showed that transgenic mice expressing the HIV-1 tat gene develop skin lesions resembling KS [119].

\section{Human immunodeficiency virus-1 trans-activating factor}

Human immunodeficiency virus-1 Tat is a viral trans-activating factor required for viral replication and expression of all HIV-1 transcripts [120]. Tat is released during acute infection of T cells by HIV. However, the protein may be internalized and activate the expression of various cellular genes in infected and non-infected cells (reviewed in [121]). 
The action of extracellular Tat is mediated by different functional regions that interact with a variety of soluble molecules, ECM components and cellular receptors (reviewed in [122]).

Biological activity of different Tat domains. After its release, Tat binds, via its basic domain, to HSPG, which are expressed on the surface of ECs and in the ECM [123]. HSPG act as low-affinity receptors for various growth factors [9]. Hence, by competing for the same heparin-binding sites, Tat may mobilize FGF2 from the ECM. Soluble, bioactive FGF2 will subsequently stimulate EC proliferation and angiogenesis [123,124]. Moreover, Tat binds to and activates the VEGF receptor VEGFR-2, which is present on ECs and on KS cells [125]. As such, Tat mimics some of the biological actions elicited by VEGF, including stimulation of EC proliferation and migration in vitro and angiogenesis and vascular permeability in vivo $[125,126]$.

Tat also activates integrins, a family of heterodimeric cell-surface receptors that mediate cellular adhesion to the ECM [124]. A well-known recognition motif that is used by several integrins to bind their specific ECM ligand is the RGD sequence, which is also present in Tat. Consequently, Tat may mimic the effect of ECM molecules, such as fibronectin and vitronectin, which promote EC adhesion to integrins $\alpha_{5} \beta_{1}$ and $\alpha_{v} \beta_{3}$, respectively. The interaction of Tat with these integrins promotes the adhesion, growth and migration of ECs in vitro and angiogenesis in vivo [124,127].

A 20-residue core domain of Tat containing seven cysteine residues was found to possess potent angiogenic activity [128]. This region is also involved in Tat-mediated recruitment of neutrophils, which secrete various angiogenic molecules, including CXCL8, VEGF and MMPs, raising the possibility that neutrophils attracted by Tat contribute to its angiogenic activity [129].

Interaction of Tat with inflammatory cytokines. In contrast to other growth factors, Tat only acts on primary ECs that are activated by pro-inflammatory cytokines, such as TNF- $\alpha$ and IFN- $\gamma$. This may be explained by the fact that these cytokines upregulate the expression of integrins and VEGFR-2 [130-132]. In vivo, additional factors are required to confer angiogenic activity to Tat. Injection of Tat alone does not promote angiogenesis nor does it induce the formation of KS-like lesions in mice $[132,133]$. However, injection of Tat together with FGF2 or with inflammatory cytokines that induce FGF2 expression results in an angiogenic response $[132,134]$. This may be explained by the angiogenic activity of FGF2 itself and also by the fact that FGF2 up-regulates the integrin receptors of Tat, resulting in a synergistic effect [132]. Inflammatory cytokines are abundantly present in AIDS patients and may cooperate with Tat to induce angiogenesis in primary KS lesions. This may account for the higher incidence and more aggressive nature of KS in HIVinfected individuals.

\section{Human cytomegalovirus}

\section{Human cytomegalovirus pathology}

Human cytomegalovirus (HCMV) is a $\beta$-herpesvirus that infects about $70 \%$ of the world's population. In healthy individuals, HCMV presents as a life-long asymptomatic infection, but in fetuses and immunocompromised individuals the virus may cause severe disease. In particular, HCMV contributes to the pathogenesis of angiogenic diseases, such as restenosis and transplant vascular sclerosis (TVS), which are characterized by chronic inflammation and concentric neointimal smooth muscle cell proliferation, resulting in vessel narrowing and ultimately allograft rejection (reviewed in [135]). Moreover, although HCMV has not been clearly implicated in human cancer, the virus seems to be specifically present in a variety of human malignancies, suggesting a possible association with cancer (reviewed in [136]).

\section{Angiogenic activity of human cytomegalovirus}

Human cytomegalovirus may infect different cell types (i.e. ECs, smooth muscle cells, pericytes, macrophages) involved in angiogenesis and stimulate angiogenesis by direct and indirect mechanisms (Figure 2). The viral UL130 gene has been identified as the major determinant of EC tropism of HCMV [137]. Infection of ECs with HCMV leads to the activation of the epidermal growth factor receptor and integrins $\beta 1$ and $\beta 3$, resulting in increased EC proliferation, motility and capillary tube formation [138].

By means of mass spectrometry and cytokine array, it was shown that HCMV induces the expression of various host cell factors implicated in angiogenesis and wound healing, including 
cytokines (e.g. IL-6...), chemokines (e.g. CXCL8, CCL2, CXCL1...), growth factors (e.g. VEGF, PlGF, PDGF...) and proteins involved in ECM remodelling (e.g. MMPs, TIMPs) (Table 1). Moreover, virus-free supernatants from HCMV-infected ECs (i.e. secretome) but not from HSV-1-infected cells induced angiogenesis and promoted vessel stabilization and EC survival in vitro [139]. IL-6 was found to be the major regulator of HCMV-induced angiogenesis through the up-regulation of the anti-apoptotic protein survivin [140]. Also, in a rat cardiac transplant model, cytomegalovirus-accelerated TVS was associated with the up-regulation of various proangiogenic genes [141]. Interestingly, many of these genes were also identified in the HCMV secretome, suggesting that HCMV-induced angiogenesis contributes to TVS disease progression.

Human cytomegalovirus encodes a constitutively activated chemokine receptor US28. US28overexpressing NIH-3T3 cells show a pro-angiogenic phenotype characterized by increased expression of VEGF [142]. Moreover, recent data demonstrate the up-regulation of COX-2 in HCMV-infected fibroblasts and in US28-overexpressing NIH-3T3 cells [143]. The increase in COX-2 expression was mediated by the activation of NF-kB and the subsequent production of VEGF (Table 2). US28 activity has also been linked to tumourigenesis, that is, US28 induces a transformed phenotype in and enhances cell cycle progression of NIH-3T3 cells. Moreover, US28-expressing cells promote tumourigenesis when injected into nude mice [142]. The pro-angiogenic and transformed phenotype was not observed in cells expressing a G proteinuncoupled mutant US28, indicating that constitutive activation of G proteins by US28 is required for the observed changes in cell behaviour [142]. Finally, transgenic mice in which US28 is targeted to intestinal epithelial cells display hyperplastic intestinal epithelium and develop adenomas and adenocarcinomas [144].

Together, these data indicate that HCMV contributes to the pathogenesis of vascular diseases by stimulating angiogenesis (reviewed in [135]). HCMV may induce (i) the expression of viral proteins (i.e. US28) with angiogenic activities, (ii) the expression and/or secretion of host angiogenic factors and (iii) inflammation, leading to the recruitment of immune cells, which amplify the angiogenic response by secreting stimulatory factors (Figure 2). Future studies will reveal whether
US28 may be regarded as a viral oncogene, similar to the constitutively activated vGPCR of KSHV.

\section{VIRUSES THAT ARE NOT ASSOCIATED WITH CANCER}

\section{Human herpesvirus 6}

Human herpesvirus 6 (HHV-6) is a $\beta$-herpesvirus, related to $\mathrm{HCMV}$, that causes the benign syndrome exanthema subitum in small children. The virus (in particular, HHV-6B) infects primarily $\mathrm{T}$ lymphocytes and subsequently establishes life-long latency. However, HHV-6 frequently reactivates in immunosuppressed patients where it may cause fatal complications, including encephalitis and myocarditis (reviewed in [145]).

Although HHV-6 is a lymphotropic virus, it has been shown to infect and replicate (although at lowlevel) in vascular and lymphatic ECs [146-149]. HHV-6 replication was demonstrated in adult heart microvascular and aortic endothelium in the absence of cytopathic effects. Moreover, HHV-6 infection of ECs resulted in the up-regulation of CCL2 (monocyte chemoattractant protein-1) and CXCL8, pro-inflammatory chemokines with angiogenic activity (Table 1) [149]. However, recent data by Caruso et al. [148] indicate that infection of (lymphatic) ECs with HHV-6 results in the inhibition of angiogenesis, as shown by the inability of the infected cells to migrate and to form capillary-like structures in vitro. The anti-angiogenic effects were shown to be associated with the expression of HHV-6 U94/rep, a latency-associated gene [148]. Further studies are required to establish the relevance of these data to HHV-6 pathology. However, because lymph nodes are a site of HHV-6 persistence, lymphatic ECs may be more relevant to HHV-6 biology than vascular ECs.

\section{Herpes simplex virus-1}

Herpes simplex virus-1 (HSV-1) is a ubiquitous $\alpha$-herpesvirus that is usually acquired during childhood. Primary infection is often subclinical or asymptomatic, after which latency is established. One of the more distressing complications caused by HSV-1 infection is herpetic stromal keratitis, which is associated with vision impairment and blindness resulting from chronic inflammation and subsequent scarring of the cornea (reviewed in [150]). 
Infection with replication-competent HSV-1 induces corneal angiogenesis associated with VEGF expression [151]. Early after infection, VEGF is evident in corneal epithelial cells, whereas in the subsequent clinical phase, inflammatory cells (i.e. neutrophils and macrophages) are the only sites of VEGF production. IL-6 produced by virus-infected cells was found to stimulate non-infected corneal and inflammatory cells in a paracrine manner to secrete VEGF [152]. HSV-1 infection of the cornea was also shown to modulate the expression of the proteases MMP-2 and MMP-9 and their endogenous inhibitors TIMP-1 and TIMP-2 (Table 1) [153,154]. MMPs are up-regulated when keratitis becomes evident, indicating that they participate in the destruction of the cornea after HSV-1 infection, whereas TIMPs are expressed during the healing process [154]. MMP-9 production requires neutrophil invasion into the cornea by replicationcompetent virus. In addition, HSV-1 infection of human keratocytes resulted in a selective downregulation of the anti-angiogenic TSP-1 and TSP-2 [155]. A critical role has also been suggested for COX-2 in HSV-1-induced keratitis [156]. The administration of a COX-2 inhibitor after HSV-1 infection resulted in reduced (i) neutrophil infiltration (ii) VEGF levels and (iii) angiogenesis in the cornea, and diminished herpetic stromal keratitis severity.

Thus, HSV-1 infection disrupts the normal equilibrium between angiogenic and anti-angiogenic factors in the (normally avascular) cornea leading to neovascularization. Unlike some other herpesviruses, HSV-1 does not appear to encode proangiogenic proteins. Instead, HSV-1 infection causes uninfected, neighbouring cells to express various angiogenesis stimulators $[151,156]$. The angiogenic response is further increased by infiltrating inflammatory cells, which are a major source of proteolytic enzymes.

\section{CONCLUDING REMARKS}

The viruses reviewed here utilize diverse biological pathways to regulate blood vessel formation, including (i) direct activation of ECs as a consequence of EC tropism, (ii) modulation of host gene expression by the activation of various host signalling pathways, (iii) expression of viral proteins with angiogenic activity and/or (iv) induction of inflammation (Figure 2). Despite these differences, several mechanisms to induce neovascularization are shared by viruses belonging to distant families.
Of importance is the finding that all human viruses known to be tumourigenic increase the activity of the transcription factor HIF-1 (the major regulator of oxygen homeostasis) under normoxic conditions (Figure 1). By stabilizing the oxygen-sensitive HIF$1 \alpha$ subunit, these viruses mimic the hypoxic condition, resulting in increased expression of various angiogenic factors under normoxia. Consequently, these viruses may deregulate the angiogenic balance in normoxic tissue and turn on the angiogenic switch in small, avascular tumours. Vascularization of the tumour will allow further tumour growth and facilitate spreading of tumour cells to distant organs. Thus, these viruses not only induce oncogenesis, but their pro-angiogenic properties may also contribute to a more aggressive tumour phenotype.

A pro-angiogenic mechanism that applies to most, if not all, viruses is induction of inflammation. This may be particularly relevant for viruses that are associated with chronic inflammation, such as HBV and HCV. Viruses typically induce an inflammatory response, which is accompanied by the release of pro-inflammatory proteins and the attraction of immune cells, which secrete various pro-angiogenic factors. A key player in the activation of a proinflammatory phenotype is the NF- $\mathrm{B}$ pathway, which is activated by viruses and is involved in the up-regulation of cellular proteins with angiogenic activity. Thus, inflammation and angiogenesis are tightly linked, and by inducing inflammation, viruses create an angiogenic environment that may favour the development/progression of angiogenic diseases or cancer.

Host factors that contribute to neovascularization and are induced by all viruses (mentioned here) are MMPs. These proteolytic enzymes are thought to facilitate spreading of the virus through tissues. However, remodelling of the ECM is also an essential step of the angiogenic cascade. Thus, a mechanism applied by viruses to promote spreading may also be utilized by ECs to invade and migrate in the extravascular space.

Finally, it should be noted that the knowledge of angiogenesis regulation by viruses is, apart for KSHV and HIV-Tat, still limited. Here, we only discussed those human viruses for which a (clear) link with angiogenesis has been established. However, recent data indicate that many more viruses may create an angiogenic phenotype; for example rhinoviruses were shown to induce 
angiogenesis by increasing the expression of VEGF [157], the clinical relevance of which remains to be determined. Adenoviruses and adenoviral vectors stimulate neovascularization, a finding that warrants further investigation, in view of their potential future use in cancer therapy [158-160]. Moreover, Dengue and Hanta viruses, which induce capillary permeability and subsequent microvascular leakage, stimulate the expression of cellular factors with pro-angiogenic activity (e.g. MMPs, Ang-2, CXCL8) [161,162]. Viruses may also inhibit blood vessel formation, as shown recently for HHV-6. Thus, various viruses may disturb the delicate balance between angiogenic and angiostatic proteins that exists in healthy tissues, the outcome of which largely depends on the tissue and cell type that is infected and/or the viral proteins being expressed.

\section{CONFLICT OF INTEREST}

The authors have no competing interest.

\section{ACKNOWLEDGEMENTS}

The authors are grateful to Prof. Lieve Naesens for critical reading of the manuscript. This work was funded by the 'Geconcerteerde Onderzoeksacties' (GOA) of the K.U.Leuven (GOA 10/014), the 'Fonds voor Wetenschappelijk Onderzoek (FWO) Vlaanderen' (Credit $n^{\circ}$ G. 0486.08) and the Centers of Excellence of the K.U.Leuven (PF/10/018).

We apologize to those authors whose work could not be cited here because of space limitations.

\section{REFERENCES}

1. Carmeliet P. Angiogenesis in life, disease and medicine. Nature 2005; 438: 932-936.

2. Liao D, Johnson RS. Hypoxia: a key regulator of angiogenesis in cancer. Cancer and Metastasis Reviews 2007; 26: 281-290.

3. Rey S, Semenza GL. Hypoxia-inducible factor-1-dependent mechanisms of vascularization and vascular remodelling. Cardiovascular Research 2010; 86: 236-242.

4. Bourboulia D, Stetler-Stevenson WG. Matrix metalloproteinases (MMPs) and tissue inhibitors of metalloproteinases (TIMPs): positive and negative regulators in tumor cell adhesion. Seminars in Cancer Biology 2010; 20: 161-168.

5. Liekens S, De Clercq E, Neyts J. Angiogenesis: regulators and clinical applications. Biochemical Pharmacology 2001; 61: 253-270.

6. Folkman J. Angiogenesis: an organizing principle for drug discovery? Nature Reviews Drug Discovery 2007; 6: 273-286.

7. Ferrara N. Vascular endothelial growth factor. Arteriosclerosis, Thrombosis, and Vascular Biology 2009; 29: 789-791.

8. Yancopoulos GD, Davis S, Gale NW, Rudge JS, Wiegand SJ, Holash J. Vascular-specific growth factors and blood vessel formation. Nature 2000; 407: 242-248.

9. Presta M, Dell'Era P, Mitola S, Moroni E, Ronca R, Rusnati M. Fibroblast growth factor/fibroblast growth factor receptor system in angiogenesis. Cytokine Growth Factor Rev 2005; 16: 159-178
10. Keeley EC, Mehrad B, Strieter RM. CXC chemokines in cancer angiogenesis and metastases. Advances in Cancer Research 2010; 106: 91-111.

11. Aggarwal BB, Shishodia S, Sandur SK, Pandey MK, Sethi G. Inflammation and cancer: how hot is the link? Biochemical Pharmacology 2006; 72: 1605-1621.

12. Cohen T, Nahari D, Cerem LW, Neufeld G, Levi BZ. Interleukin 6 induces the expression of vascular endothelial growth factor. The Journal of Biological Chemistry 1996; 271: 736-741.

13. Yao JS, Zhai W, Young WL, Yang GY. Interleukin-6 triggers human cerebral endothelial cells proliferation and migration: the role for KDR and MMP-9. Biochemical and Biophysical Research Communications 2006; 342: 1396-1404.

14. Greenhough A, Smartt HJ, Moore AE, et al. The COX-2/PGE2 pathway: key roles in the hallmarks of cancer and adaptation to the tumour microenvironment. Carcinogenesis 2009; 30: 377-386.

15. Tello-Montoliu A, Patel JV, Lip GY. Angiogenin: a review of the pathophysiology and potential clinical applications. Journal of Thrombosis and Haemostasis 2006; 4: $1864-1874$.

16. Bronckaers A, Gago F, Balzarini J, Liekens S. The dual role of thymidine phosphorylase in cancer development and chemotherapy. Medicinal Research Reviews 2009; 29: 903-953.
17. Contois L, Akalu A, Brooks PC. Integrins as "functional hubs" in the regulation of pathological angiogenesis. Seminars in Cancer Biology 2009; 19: 318-328.

18. Dejana E, Tournier-Lasserve E, Weinstein BM. The control of vascular integrity by endothelial cell junctions: molecular basis and pathological implications. Developmental Cell 2009; 16: 209-221.

19. Martin D, Gutkind JS. Human tumorassociated viruses and new insights into the molecular mechanisms of cancer. Oncogene 2008; 27 Suppl 2: S31-S42.

20. Young LS, Rickinson AB. Epstein-Barr virus: 40 years on. Nature Reviews. Cancer 2004; 4: 757-768.

21. Yoshizaki T, Horikawa T, Qing-Chun R, et al. Induction of interleukin-8 by Epstein-Barr virus latent membrane protein-1 and its correlation to angiogenesis in nasopharyngeal carcinoma. Clinical Cancer Research 2001; 7: 1946-1951.

22. Tsuji A, Wakisaka N, Kondo S, Murono S, Furukawa $\mathrm{M}$, Yoshizaki T. Induction of receptor for advanced glycation end products by EBV latent membrane protein 1 and its correlation with angiogenesis and cervical lymph node metastasis in nasopharyngeal carcinoma. Clinical Cancer Research 2008; 14: 5368-5375.

23. Murono $\mathrm{S}$, Inoue $\mathrm{H}$, Tanabe $\mathrm{T}$, et al. Induction of cyclooxygenase-2 by EpsteinBarr virus latent membrane protein 1 is involved in vascular endothelial growth 
factor production in nasopharyngeal carcinoma cells. Proceedings of the National Academy of Sciences of the United States of America 2001; 98: 6905-6910.

24. Horikawa T, Yoshizaki T, Sheen TS, Lee SY, Furukawa M. Association of latent membrane protein 1 and matrix metalloproteinase 9 with metastasis in nasopharyngeal carcinoma. Cancer 2000; 89: 715-723.

25. Chen CC, Chen LC, Liang Y, Tsang NM, Chang YS. Epstein-Barr virus latent membrane protein 1 induces the chemotherapeutic target, thymidine phosphorylase, via NF-kappaB and p38 MAPK pathways. Cellular Signalling 2010; 22: 1132-1142.

26. Paydas S, Ergin M, Erdogan S, Seydaoglu G. Prognostic significance of EBV-LMP1 and VEGF-A expressions in non-Hodgkin's lymphomas. Leukemia Research 2008; 32: 1424-1430.

27. Mosialos G, Birkenbach M, Yalamanchili R, VanArsdale T, Ware C, Kieff E. The Epstein-Barr virus transforming protein LMP1 engages signaling proteins for the tumor necrosis factor receptor family. Cell 1995; 80: 389-399.

28. Kondo S, Seo SY, Yoshizaki T, et al. EBV latent membrane protein 1 up-regulates hypoxia-inducible factor 1alpha through Siah1-mediated down-regulation of prolyl hydroxylases 1 and 3 in nasopharyngeal epithelial cells. Cancer Research 2006; 66: 9870-9877.

29. Wakisaka N, Kondo S, Yoshizaki T, Murono S, Furukawa M, Pagano JS. Epstein-Barr virus latent membrane protein 1 induces synthesis of hypoxiainducible factor 1 alpha. Molecular and Cellular Biology 2004; 24: 5223-5234.

30. Wakisaka N, Murono S, Yoshizaki T, Furukawa M, Pagano JS. Epstein-Barr virus latent membrane protein 1 induces and causes release of fibroblast growth factor-2. Cancer Research 2002; 62: 6337-6344.

31. Yoshizaki T, Sato H, Furukawa M, Pagano JS. The expression of matrix metalloproteinase 9 is enhanced by EpsteinBarr virus latent membrane protein 1 . Proceedings of the National Academy of Sciences of the United States of America 1998; 95: 3621-3626.

32. Lu J, Chua HH, Chen SY, Chen JY, Tsai CH. Regulation of matrix metalloproteinase-1 by Epstein-Barr virus proteins. Cancer Research 2003; 63: 256-262.

33. Stevenson D, Charalambous C, Wilson JB. Epstein-Barr virus latent membrane protein 1 (CAO) up-regulates VEGF and TGF alpha concomitant with hyperlasia, with subsequent up-regulation of p16 and MMP9. Cancer Research 2005; 65: 8826-8835.

34. O'Neil JD, Owen TJ, Wood VH, et al. Epstein-Barr virus-encoded EBNA1 modulates the AP-1 transcription factor pathway in nasopharyngeal carcinoma cells and enhances angiogenesis in vitro. The Journal of General Virology 2008; 89: 2833-2842.

35. Sakakibara S, Tosato G. Regulation of angiogenesis in malignancies associated with Epstein-Barr virus and Kaposi's sarcoma-associated herpes virus. Future Microbiology 2009; 4: 903-917.

36. Mesri EA, Cesarman E, Boshoff C. Kaposi's sarcoma and its associated herpesvirus. Nature Reviews. Cancer 2010; 10: 707-719.

37. Boshoff C, Schulz TF, Kennedy MM, et al. Kaposi's sarcoma-associated herpesvirus infects endothelial and spindle cells. Nature Medicine 1995; 1: 1274-1278.

38. Chiou CJ, Poole LJ, Kim PS, et al. Patterns of gene expression and a transactivation function exhibited by the vGCR (ORF74) chemokine receptor protein of Kaposi's sarcoma-associated herpesvirus. Journal of Virology 2002; 76: 3421-3439.

39. Naranatt PP, Krishnan HH, Svojanovsky SR, Bloomer C, Mathur S, Chandran B. Host gene induction and transcriptional reprogramming in Kaposi's sarcomaassociated herpesvirus (KSHV/HHV-8)infected endothelial, fibroblast, and B cells: insights into modulation events early during infection. Cancer Research 2004; 64: 72-84.

40. Poole LJ, Yu Y, Kim PS, Zheng QZ, Pevsner J, Hayward GS. Altered patterns of cellular gene expression in dermal microvascular endothelial cells infected with Kaposi's sarcoma-associated herpesvirus. Journal of Virology 2002; 76: 3395-3420.

41. Sivakumar R, Sharma-Walia N, Raghu H, et al. Kaposi's sarcoma-associated herpesvirus induces sustained levels of vascular endothelial growth factors A and C early during in vitro infection of human microvascular dermal endothelial cells: biological implications. Journal of Virology 2008; 82: 1759-1776.

42. Sadagopan S, Sharma-Walia N, Veettil MV, et al. Kaposi's sarcoma-associated herpesvirus upregulates angiogenin during infection of human dermal microvascular endothelial cells, which induces $45 \mathrm{~S}$ rRNA synthesis, antiapoptosis, cell proliferation, migration, and angiogenesis. Journal of Virology 2009; 83: 3342-3364.

43. Ye FC, Blackbourn DJ, Mengel M, et al. Kaposi's sarcoma-associated herpesvirus promotes angiogenesis by inducing angiopoietin-2 expression via AP-1 and Ets1. Journal of Virology 2007; 81: 3980-3991.

44. Sharma-Walia N, Paul AG, Bottero V, et al. Kaposi's sarcoma associated herpes virus (KSHV) induced COX-2: a key factor in latency, inflammation, angiogenesis, cell survival and invasion. PLoS Pathogens 2010; 6: e1000777.

45. Lane BR, Liu J, Bock PJ, et al. Interleukin-8 and growth-regulated oncogene alpha mediate angiogenesis in Kaposi's sarcoma. Journal of Virology 2002; 76: 11570-11583.

46. Qian LW, Xie J, Ye F, Gao SJ. Kaposi's sarcoma-associated herpesvirus infection promotes invasion of primary human umbilical vein endothelial cells by inducing matrix metalloproteinases. Journal of Virology 2007; 81: 7001-7010.

47. Carroll PA, Kenerson HL, Yeung RS, Lagunoff M. Latent Kaposi's sarcomaassociated herpesvirus infection of endothelial cells activates hypoxia-induced factors. Journal of Virology 2006; 80: 10802-10812.

48. Qian LW, Greene W, Ye F, Gao SJ. Kaposi's sarcoma-associated herpesvirus disrupts adherens junctions and increases endothelial permeability by inducing degradation of VE-cadherin. Journal of Virology 2008; 82: 11902-11912.

49. Watanabe T, Sugaya M, Atkins AM, et al. Kaposi's sarcoma-associated herpesvirus latency-associated nuclear antigen prolongs the life span of primary human umbilical vein endothelial cells. Journal of Virology 2003; 77: 6188-6196. 
50. Cai Q, Murakami M, Si H, Robertson ES. A potential alpha-helix motif in the amino terminus of LANA encoded by Kaposi's sarcoma-associated herpesvirus is critical for nuclear accumulation of HIF-1alpha in normoxia. Journal of Virology 2007; 81: 10413-10423.

51. Sakakibara S, Pise-Masison CA, Brady JN, Tosato G. Gene regulation and functional alterations induced by Kaposi's sarcoma-associated herpesvirus-encoded ORFK13/vFLIP in endothelial cells. Journal of Virology 2009; 83: 2140-2153.

52. Samols MA, Skalsky RL, Maldonado $\mathrm{AM}$, et al. Identification of cellular genes targeted by KSHV-encoded microRNAs. PLoS Pathogens 2007; 3: e65.

53. Anand S, Majeti BK, Acevedo LM, et al. MicroRNA-132-mediated loss of p120RasGAP activates the endothelium to facilitate pathological angiogenesis. Nature Medicine 2010; 16: 909-914.

54. Boshoff C, Endo Y, Collins PD, et al. Angiogenic and HIV-inhibitory functions of KSHV-encoded chemokines. Science 1997; 278: 290-294.

55. Stine JT, Wood C, Hill M, et al. KSHVencoded CC chemokine vMIP-III is a CCR4 agonist, stimulates angiogenesis, and selectively chemoattracts TH2 cells. Blood 2000; 95: 1151-1157.

56. Cherqui S, Kingdon KM, Thorpe C, Kurian SM, Salomon DR. Lentiviral gene delivery of vMIP-II to transplanted endothelial cells and endothelial progenitors is proangiogenic in vivo. Molecular Therapy 2007; 15: 1264-1272.

57. Aoki Y, Jaffe ES, Chang Y, et al. Angiogenesis and hematopoiesis induced by Kaposi's sarcoma-associated herpesvirus-encoded interleukin-6. Blood 1999; 93: 4034-4043.

58. Vart RJ, Nikitenko LL, Lagos D, et al. Kaposi's sarcoma-associated herpesvirusencoded interleukin-6 and G-proteincoupled receptor regulate angiopoietin-2 expression in lymphatic endothelial cells. Cancer Research 2007; 67: 4042-4051.

59. Shin YC, Joo CH, Gack MU, Lee HR, Jung JU. Kaposi's sarcoma-associated herpesvirus viral IFN regulatory factor 3 stabilizes hypoxia-inducible factor-1 alpha to induce vascular endothelial growth factor expression. Cancer Research 2008; 68: 1751-1759.
60. Wang L, Wakisaka N, Tomlinson CC, et al. The Kaposi's sarcoma-associated herpesvirus (KSHV/HHV-8) K1 protein induces expression of angiogenic and invasion factors. Cancer Research 2004; 64: 2774-2781.

61. Arvanitakis L, Geras-Raaka E, Varma A, Gershengorn MC, Cesarman E. Human herpesvirus KSHV encodes a constitutively active G-protein-coupled receptor linked to cell proliferation. Nature 1997; 385: 347-350.

62. Bais C, Van Geelen A, Eroles P, et al. Kaposi's sarcoma associated herpesvirus G protein-coupled receptor immortalizes human endothelial cells by activation of the VEGF receptor-2/ KDR. Cancer Cell 2003; 3: 131-143.

63. Sodhi A, Montaner S, Patel V, et al. Akt plays a central role in sarcomagenesis induced by Kaposi's sarcoma herpesvirusencoded G protein-coupled receptor. Proceedings of the National Academy of Sciences of the United States of America 2004; 101: 4821-4826.

64. Sodhi A, Chaisuparat R, Hu J, et al. The TSC2/mTOR pathway drives endothelial cell transformation induced by the Kaposi's sarcoma-associated herpesvirus $\mathrm{G}$ protein-coupled receptor. Cancer Cell 2006; 10: 133-143.

65. Sodhi A, Montaner S, Patel V, et al. The Kaposi's sarcoma-associated herpes virus $G$ protein-coupled receptor up-regulates vascular endothelial growth factor expression and secretion through mitogenactivated protein kinase and p38 pathways acting on hypoxia-inducible factor 1alpha. Cancer Research 2000; 60: 4873-4880.

66. Burger M, Hartmann T, Burger JA, Schraufstatter I. KSHV-GPCR and CXCR2 transforming capacity and angiogenic responses are mediated through a JAK2STAT3-dependent pathway. Oncogene 2005; 24: 2067-2075.

67. Pati S, Cavrois M, Guo HG, et al. Activation of NF-kappaB by the human herpesvirus 8 chemokine receptor ORF74: evidence for a paracrine model of Kaposi's sarcoma pathogenesis. Journal of Virology 2001; 75: 8660-8673.

68. Polson AG, Wang D, DeRisi J, Ganem D. Modulation of host gene expression by the constitutively active $\mathrm{G}$ protein-coupled receptor of Kaposi's sarcoma-associated herpesvirus. Cancer Research 2002; 62: 4525-4530.

69. Yen-Moore A, Hudnall SD, Rady PL, et al. Differential expression of the HHV-8 vGCR cellular homolog gene in AIDSassociated and classic Kaposi's sarcoma: potential role of HIV-1 Tat. Virology 2000; 267: 247-251.

70. Yugawa T, Kiyono T. Molecular mechanisms of cervical carcinogenesis by high-risk human papillomaviruses: novel functions of E6 and E7 oncoproteins. Reviews in Medical Virology 2009; 19: 97-113.

71. Nair P, Gangadevi T, Jayaprakash P, Nair M, Nair M, Pillai M. Increased angiogenesis in the uterine cervix associated with human papillomavirus infection. Pathology, Research and Practice 1999; 195: 163-169.

72. Mullerat J, Wong Te Fong LF, Davies SE, Winslet MC, Perrett CW. Angiogenesis in anal warts, anal intraepithelial neoplasia and anal squamous cell carcinoma. Colorectal Disease 2003; 5: 353-357.

73. Harada K, Lu S, Chisholm DM, Syrjanen S, Schor AM. Angiogenesis and vasodilation in skin warts. Association with HPV infection. Anticancer Res 2000; 20: 4519-4523.

74. Lopez-Ocejo O, Viloria-Petit A, BequetRomero M, Mukhopadhyay D, Rak J, Kerbel RS. Oncogenes and tumor angiogenesis: the HPV-16 E6 oncoprotein activates the vascular endothelial growth factor (VEGF) gene promoter in a p53 independent manner. Oncogene 2000; 19: 4611-4620.

75. Bequet-Romero M, Lopez-Ocejo O. Angiogenesis modulators expression in culture cell lines positives for HPV-16 oncoproteins. Biochemical and Biophysical Research Communications 2000; 277: 55-61.

76. Xi L, Wang S, Wang C, et al. The proangiogenic factors stimulated by human papillomavirus type $16 \mathrm{E} 6$ and E7 protein in C33A and human fibroblasts. Oncology Reports 2009; 21: 25-31.

77. Chen W, Li F, Mead L, et al. Human papillomavirus causes an angiogenic switch in keratinocytes which is sufficient to alter endothelial cell behavior. Virology 2007; 367: 168-174. 
78. Toussaint-Smith E, Donner DB, Roman A. Expression of human papillomavirus type 16 E6 and E7 oncoproteins in primary foreskin keratinocytes is sufficient to alter the expression of angiogenic factors. Oncogene 2004; 23: 2988-2995.

79. Kim SH, Juhnn YS, Kang S, et al. Human papillomavirus 16 E5 up-regulates the expression of vascular endothelial growth factor through the activation of epidermal growth factor receptor, MEK/ ERK1,2 and PI3K/Akt. Cellular and Molecular Life Sciences 2006; 63: 930-938.

80. Tang X, Zhang Q, Nishitani J, Brown J, Shi S, Le AD. Overexpression of human papillomavirus type 16 oncoproteins enhances hypoxia-inducible factor 1 alpha protein accumulation and vascular endothelial growth factor expression in human cervical carcinoma cells. Clinical Cancer Research 2007; 13: 2568-2576.

81. Dameron KM, Volpert OV, Tainsky MA, Bouck N. Control of angiogenesis in fibroblasts by $\mathrm{p} 53$ regulation of thrombospondin1. Science 1994; 265: 1582-1584.

82. Ravi R, Mookerjee B, Bhujwalla ZM, et al. Regulation of tumor angiogenesis by $\mathrm{p} 53-$ induced degradation of hypoxia-inducible factor c. Genes \& Development 2000; 14: $34-44$

83. Smola-Hess S, Pahne J, Mauch C, Zigrino P, Smola H, Pfister HJ. Expression of membrane type 1 matrix metalloproteinase in papillomavirus-positive cells: role of the human papillomavirus (HPV) 16 and HPV8 E7 gene products. The Journal of General Virology 2005; 86: 1291-1296.

84. Le BH, Lachgar A, D'Anna R, et al. Induction of cellular immunosuppression by the human papillomavirus type $16 \mathrm{E} 7$ oncogenic protein. Biomedicine \& Pharmacotherapy 1999; 53: 323-328.

85. D'Anna R, Le BH, Alessandri G, et al. Selective activation of cervical microvascular endothelial cells by human papillomavirus 16-e7 oncoprotein. Journal of the National Cancer Institute 2001; 93: 1843-1851.

86. Fule T, Mathe M, Suba Z, et al. The presence of human papillomavirus 16 in neural structures and vascular endothelial cells. Virology 2006; 348: 289-296.
87. Tsai WL, Chung RT. Viral hepatocarcinogenesis. Oncogene 2010; 29: 2309-2324.

88. Semela D, Dufour JF. Angiogenesis and hepatocellular carcinoma. Journal of $\mathrm{He}$ patology 2004; 41: 864-880.

89. Lee SW, Lee YM, Bae SK, Murakami S, Yun Y, Kim KW. Human hepatitis B virus $\mathrm{X}$ protein is a possible mediator of hypoxia-induced angiogenesis in hepatocarcinogenesis. Biochemical and Biophysical Research Communications 2000; 268: 456-461.

90. Yun C, Lee JH, Wang JH, et al. Expression of hepatitis B virus $\mathrm{X}(\mathrm{HBx})$ gene is upregulated by adriamycin at the posttranscriptional level. Biochemical and Biophysical Research Communications 2002; 296: 1157-1163.

91. Moon EJ, Jeong $\mathrm{CH}$, Jeong JW, et al. Hepatitis B virus $X$ protein induces angiogenesis by stabilizing hypoxia-inducible factor-1alpha. The FASEB Journal 2004; 18: 382-384.

92. Yoo YG, Oh SH, Park ES, et al. Hepatitis $B$ virus $X$ protein enhances transcriptional activity of hypoxia-inducible factor1alpha through activation of mitogenactivated protein kinase pathway. The Journal of Biological Chemistry 2003; 278: 39076-39084.

93. Park YN, Kim YB, Yang KM, Park C. Increased expression of vascular endothelial growth factor and angiogenesis in the early stage of multistep hepatocarcinogenesis. Archives of Pathology \& Laboratory Medicine 2000; 124: 1061-1065.

94. Dai CX, Gao Q, Qiu SJ, et al. Hypoxiainducible factor-1 alpha, in association with inflammation, angiogenesis and MYC, is a critical prognostic factor in patients with HCC after surgery. BMC Cancer 2009; 9: 418.

95. Sanz-Cameno P, Martin-Vilchez S, Lara-Pezzi E, et al. Hepatitis B virus promotes angiopoietin-2 expression in liver tissue: role of $\mathrm{HBV} x$ protein. The American Journal of Pathology 2006; 169: 1215-1222.

96. Chen ZB, Shen SQ, Ding YM, et al. The angiogenic and prognostic implications of VEGF, Ang-1, Ang-2, and MMP-9 for hepatocellular carcinoma with background of hepatitis B virus. Medical Oncology 2009; 26: 365-371.
97. Lara-Pezzi E, Gomez-Gaviro MV, Galvez BG, et al. The hepatitis B virus $\mathrm{X}$ protein promotes tumor cell invasion by inducing membrane-type matrix metalloproteinase-1 and cyclooxygenase-2 expression. Journal of Clinical Investigation 2002; 110: 1831-1838.

98. Ou DP, Tao YM, Tang FQ, Yang LY. The hepatitis $\mathrm{B}$ virus $\mathrm{X}$ protein promotes hepatocellular carcinoma metastasis by upregulation of matrix metalloproteinases. International Journal of Cancer 2007; 120: 1208-1214.

99. Yu FL, Liu HJ, Lee JW, Liao MH, Shih WL. Hepatitis B virus $X$ protein promotes cell migration by inducing matrix metalloproteinase-3. Journal of Hepatology 2005; 42: 520-527.

100. Chung TW, Lee YC, Kim CH. Hepatitis B viral HBx induces matrix metalloproteinase-9 gene expression through activation of ERK and PI-3K/AKT pathways: involvement of invasive potential. The FASEB Journal 2004; 18: 1123-1125.

101. Zhang J, Niu D, Sui J, Ching CB, Chen WN. Protein profile in hepatitis B virus replicating rat primary hepatocytes and HepG2 cells by iTRAQ-coupled 2-D LCMS/MS analysis: insights on liver angiogenesis. Proteomics 2009; 9: 2836-2845.

102. Salcedo X, Medina J, Sanz-Cameno P, et al. The potential of angiogenesis soluble markers in chronic hepatitis C. Hepatology 2005; 42: 696-701.

103. Gabriel A, Kukla M, Wilk M, Liszka L, Petelenz M, Musialik J. Angiogenesis in chronic hepatitis $\mathrm{C}$ is associated with inflammatory activity grade and fibrosis stage. Pathology, Research and Practice 2009; 205: 758-764.

104. Messerini L, Novelli L, Comin CE. Microvessel density and clinicopathological characteristics in hepatitis $C$ virus and hepatitis $B$ virus related hepatocellular carcinoma. Journal of Clinical Pathology 2004; 57: 867-871.

105. Nasimuzzaman M, Waris G, Mikolon D, Stupack DG, Siddiqui A. Hepatitis C virus stabilizes hypoxia-inducible factor 1alpha and stimulates the synthesis of vascular endothelial growth factor. Journal of Virology 2007; 81: 10249-10257.

106. Gong G, Waris G, Tanveer R, Siddiqui A. Human hepatitis $C$ virus NS5A protein 
alters intracellular calcium levels, induces oxidative stress, and activates STAT- 3 and NF-kappa B. Proceedings of the National Academy of Sciences of the United States of America 2001; 98: 9599-9604.

107. Hassan M, Selimovic D, Ghozlan H, Abdel-kader O. Hepatitis C virus core protein triggers hepatic angiogenesis by a mechanism including multiple pathways. Hepatology 2009; 49: 1469-1482.

108. Li Y, Chen J, Wu C, Wang L, Lu M, Chen X. Hepatitis B virus/hepatitis $C$ virus upregulate angiopoietin-2 expression through mitogen-activated protein kinase pathway. Hepatology Research 2010; 40: 1022-1033.

109. Shin JY, Hur W, Wang JS, et al. HCV core protein promotes liver fibrogenesis via upregulation of CTGF with TGF-beta1. Experimental \& Molecular Medicine 2005; 37: 138-145.

110. Mazzocca A, Sciammetta SC, Carloni V, et al. Binding of hepatitis $C$ virus envelope protein E2 to CD81 up-regulates matrix metalloproteinase-2 in human hepatic stellate cells. The Journal of Biological Chemistry 2005; 280: 11329-11339.

111. Nunez O, Fernandez-Martinez A, Majano $\mathrm{PL}$, et al. Increased intrahepatic cyclooxygenase 2, matrix metalloproteinase 2, and matrix metalloproteinase 9 expression is associated with progressive liver disease in chronic hepatitis $C$ virus infection: role of viral core and NS5A proteins. Gut 2004; 53: 1665-1672.

112. Matsuoka M, Jeang KT. Human T-cell leukaemia virus type 1 (HTLV-1) infectivity and cellular transformation. Nature Reviews. Cancer 2007; 7: 270-280.

113. Bazarbachi A, Abou MR, Gessain A, et al. Human T-cell lymphotropic virus type I-infected cells extravasate through the endothelial barrier by a local angiogenesislike mechanism. Cancer Research 2004; 64: 2039-2046.

114. Hayashibara T, Yamada Y, Miyanishi T, et al. Vascular endothelial growth factor and cellular chemotaxis: a possible autocrine pathway in adult T-cell leukemia cell invasion. Clinical Cancer Research 2001; 7: 2719-2726.

115. El-Sabban ME, Merhi RA, Haidar HA, et al. Human T-cell lymphotropic virus type 1transformed cells induce angiogenesis and establish functional gap junctions with endothelial cells. Blood 2002; 99: 3383-3389.

116. Kchour G, Makhoul NJ, Mahmoudi M et al. Zidovudine and interferon-alpha treatment induces a high response rate and reduces HTLV-1 proviral load and VEGF plasma levels in patients with adult T-cell leukemia from North East Iran. Leukaemia E Lymphoma 2007; 48: 330-336.

117. Kchour G, Tarhini M, Sharifi N et al. Increased microvessel density in involved organs from patients with HTLV-I associated adult T cell leukemia lymphoma. Leukaemia \& Lymphoma 2008; 49: 265-270.

118. Watters KM, Dean J, Gautier V, Hall WW, Sheehy N. Tax 1-independent induction of vascular endothelial growth factor in adult T-cell leukemia caused by human T-cell leukemia virus type 1 . Journal of Virology 2010; 84: 5222-5228.

119. Vogel J, Hinrichs SH, Reynolds RK, Luciw PA, Jay G. The HIV tat gene induces dermal lesions resembling Kaposi's sarcoma in transgenic mice. Nature 1988; 335: 606-611.

120. Arya SK, Guo C, Josephs SF, WongStaal F. Trans-activator gene of human T-lymphotropic virus type III (HTLV-III). Science 1985; 229: 69-73.

121. Barillari G, Ensoli B. Angiogenic effects of extracellular human immunodeficiency virus type 1 Tat protein and its role in the pathogenesis of AIDS-associated Kaposi's sarcoma. Clinical Microbiology Reviews 2002; 15: 310-326.

122. Rusnati M, Presta M. HIV-1 Tat protein and endothelium: from protein/cell interaction to AIDS-associated pathologies. Angiogenesis 2002; 5: 141-151.

123. Albini A, Benelli R, Presta M, et al. HIV-tat protein is a heparin-binding angiogenic growth factor. Oncogene 1996; 12: 289-297.

124. Barillari G, Sgadari C, Fiorelli V, et al. The Tat protein of human immunodeficiency virus type-1 promotes vascular cell growth and locomotion by engaging the alpha5beta1 and alphavbeta3 integrins and by mobilizing sequestered basic fibroblast growth factor. Blood 1999; 94: 663-672.

125. Albini A, Soldi R, Giunciuglio D, et al. The angiogenesis induced by HIV-1 tat protein is mediated by the Flk-1/KDR receptor on vascular endothelial cells. Nature Medicine 1996; 2: 1371-1375.
126. Toschi E, Bacigalupo I, Strippoli R, et al. HIV-1 Tat regulates endothelial cell cycle progression via activation of the Ras/ ERK MAPK signaling pathway. Molecular Biology of the Cell 2006; 17: 1985-1994.

127. Urbinati C, Mitola S, Tanghetti E, et al. Integrin alphavbeta3 as a target for blocking HIV-1 Tat-induced endothelial cell activation in vitro and angiogenesis in vivo. Arteriosclerosis, Thrombosis, and Vascular Biology 2005; 25: 2315-2320.

128. Boykins RA, Mahieux R, Shankavaram UT, et al. Cutting edge: a short polypeptide domain of HIV-1-Tat protein mediates pathogenesis. Journal of Immunology 1999; 163: 15-20.

129. Benelli R, Barbero A, Ferrini S, et al. Human immunodeficiency virus transactivator protein (Tat) stimulates chemotaxis, calcium mobilization, and activation of human polymorphonuclear leukocytes: implications for Tat-mediated pathogenesis. The Journal of Infectious Diseases 2000; 182: 1643-1651.

130. Albini A, Barillari G, Benelli R, Gallo RC, Ensoli B. Angiogenic properties of human immunodeficiency virus type 1 Tat protein. Proceedings of the National Academy of Sciences of the United States of America 1995; 92: 4838-4842.

131. Fiorelli V, Barillari G, Toschi E, et al. IFNgamma induces endothelial cells to proliferate and to invade the extracellular matrix in response to the HIV-1 Tat protein: implications for AIDS-Kaposi's sarcoma pathogenesis. Journal of Immunology 1999; 162: 1165-1170.

132. Barillari G, Sgadari C, Palladino C, et al. Inflammatory cytokines synergize with the HIV-1 Tat protein to promote angiogenesis and Kaposi's sarcoma via induction of basic fibroblast growth factor and the alpha $\mathrm{v}$ beta 3 integrin. Journal of Immunology 1999; 163: 1929-1935.

133. Corallini A, Altavilla G, Pozzi L, et al. Systemic expression of HIV-1 tat gene in transgenic mice induces endothelial proliferation and tumors of different histotypes. Cancer Research 1993; 53: 5569-5575.

134. Ensoli B, Gendelman R, Markham P, et al. Synergy between basic fibroblast growth factor and HIV-1 Tat protein in induction of Kaposi's sarcoma. Nature 1994; 371: 674-680. 
135. Caposio P, Orloff SL, Streblow DN. The role of cytomegalovirus in angiogenesis. Virus Research 1 October 2010 [Epub ahead of print].

136. Soroceanu L, Cobbs CS. Is HCMV a tumor promoter? Virus Research 29 October 2010 [Epub ahead of print].

137. Schuessler A, Sampaio KL, Scrivano L, Sinzger C. Mutational mapping of UL130 of human cytomegalovirus defines peptide motifs within the C-terminal third as essential for endothelial cell infection. Journal of Virology 2010; 84: 9019-9026.

138. Bentz GL, Yurochko AD. Human CMV infection of endothelial cells induces an angiogenic response through viral binding to EGF receptor and beta1 and beta3 integrins. Proceedings of the National Academy of Sciences of the United States of America 2008; 105: 5531-5536.

139. Dumortier J, Streblow DN, Moses AV, et al. Human cytomegalovirus secretome contains factors that induce angiogenesis and wound healing. Journal of Virology 2008; 82: 6524-6535.

140. Botto S, Streblow DN, Defilippis V, et al. IL-6 in human cytomegalovirus secretome promotes angiogenesis and survival of endothelial cells through the stimulation of survivin. Blood 2011; 117(1): 352-361.

141. Streblow DN, Kreklywich CN, Andoh T, et al. The role of angiogenic and wound repair factors during $\mathrm{CMV}$-accelerated transplant vascular sclerosis in rat cardiac transplants. American Journal of Transplantation 2008; 8: 277-287.

142. Maussang D, Verzijl D, van Walsum M, et al. Human cytomegalovirus-encoded chemokine receptor US28 promotes tumorigenesis. Proceedings of the National Academy of Sciences of the United States of America 2006; 103: 13068-13073.

143. Maussang D, Langemeijer E, Fitzsimons $\mathrm{CP}$, et al. The human cytomegalovirusencoded chemokine receptor US28 promotes angiogenesis and tumor formation via cyclooxygenase-2. Cancer Research 2009; 69: 2861-2869.

144. Bongers G, Maussang D, Muniz LR et al. The cytomegalovirus-encoded chemokine receptor US28 promotes intestinal neoplasia in transgenic mice. Journal of Clinical Investigation 2010; 120: 3969-3978.
145. De Bolle L, Naesens L, De Clercq E. Update on human herpesvirus 6 biology, clinical features, and therapy. Clinical Microbiology Reviews 2005; 18: 217-245.

146. Wu CA, Shanley JD. Chronic infection of human umbilical vein endothelial cells by human herpesvirus- 6 . The Journal of General Virology 1998; 79 (Pt 5): 1247-1256.

147. Rotola A, Di Luca D, Cassai E, et al. Human herpesvirus 6 infects and replicates in aortic endothelium. Journal of Clinical Microbiology 2000; 38: 3135-3136.

148. Caruso A, Caselli E, Fiorentini S, et al. U94 of human herpesvirus 6 inhibits in vitro angiogenesis and lymphangiogenesis. Proceedings of the National Academy of Sciences of the United States of America 2009; 106: 20446-20451.

149. Caruso A, Rotola A, Comar M, et al. HHV-6 infects human aortic and heart microvascular endothelial cells, increasing their ability to secrete proinflammatory chemokines. Journal of Medical Virology 2002; 67: 528-533.

150. Kaye S, Choudhary A. Herpes simplex keratitis. Progress in Retinal and Eye Research 2006; 25: 355-380.

151. Zheng M, Deshpande S, Lee S, Ferrara N, Rouse BT. Contribution of vascular endothelial growth factor in the neovascularization process during the pathogenesis of herpetic stromal keratitis. Journal of Virology 2001; 75: 9828-9835.

152. Biswas PS, Banerjee K, Kinchington PR, Rouse BT. Involvement of IL-6 in the paracrine production of VEGF in ocular HSV-1 infection. Experimental Eye Research 2006; 82: 46-54.

153. Lee S, Zheng M, Kim B, Rouse BT. Role of matrix metalloproteinase-9 in angiogenesis caused by ocular infection with herpes simplex virus. Journal of Clinical Investigation 2002; 110: 1105-1111.

154. Yang YN, Bauer D, Wasmuth S, Steuhl KP, Heiligenhaus A. Matrix metalloproteinases (MMP-2 and 9) and tissue inhibitors of matrix metalloproteinases (TIMP-1 and 2) during the course of experimental necrotizing herpetic keratitis. Experimental Eye Research 2003; 77: 227-237.
155. Choudhary A, Hiscott P, Hart CA, Kaye SB, Batterbury M, Grierson I. Suppression of thrombospondin 1 and 2 production by herpes simplex virus 1 infection in cultured keratocytes. Molecular Vision 2005; 11: 163-168.

156. Biswas PS, Banerjee K, Kim B, KinchingtonPR, Rouse BT. Role of inflammatory cytokine-induced cyclooxygenase 2 in the ocular immunopathologic disease herpetic stromal keratitis. Journal of Virology 2005; 79: 10589-10600.

157. Psarras S, Volonaki E, Skevaki CL, et al. Vascular endothelial growth factormediated induction of angiogenesis by human rhinoviruses. The Journal of Allergy and Clinical Immunology 2006; 117: 291-297.

158. Kuhn H, Riedel A, Eichler W, Aust G, Gessner $\mathrm{C}$, Wirtz $\mathrm{H}$. Influence of adenoviral vector on expression of angiogenesis regulating factors in non-small cell lung cancer cell lines. Cancer Immunology, Immunotherapy 2002; 51: 461-466.

159. Seandel M, Butler JM, Kobayashi $\mathrm{H}$, et al. Generation of a functional and durable vascular niche by the adenoviral E4ORF1 gene. Proceedings of the National Academy of Sciences of the United States of America 2008; 105: 19288-19293.

160. Kornberg LJ, Grant MB. Adenoviruses increase endothelial cell proliferation, migration, and tube formation: partial reversal by the focal adhesion kinase inhibitor, FRNK. Microvascular Research 2007; 73: 157-162.

161. Basu A, Chaturvedi UC. Vascular endothelium: the battlefield of dengue viruses. FEMS Immunology and Medical Microbiology 2008; 53: 287-299.

162. Mackow ER, Gavrilovskaya IN. Hantavirus regulation of endothelial cell functions. Thrombosis and Haemostasis 2009; 102: 1030-1041.

163. Wang Z, Luo F, Li L, et al. STAT3 activation induced by Epstein-Barr virus latent membrane protein1 causes vascular endothelial growth factor expression and cellular invasiveness via JAK3 And ERK signaling. European Journal of Cancer 2010; 46(16): 2996-3006.

164. Wood VH, O'Neil JD, Wei W, Stewart $\mathrm{SE}$, Dawson CW, Young LS. Epstein- 
Barr virus-encoded EBNA1 regulates cellular gene transcription and modulates the STAT1 and TGFbeta signaling pathways. Oncogene 2007; 26: 4135-4147.

165. An J, Lichtenstein AK, Brent G, Rettig MB. The Kaposi sarcoma-associated herpesvirus (KSHV) induces cellular interleukin 6 expression: role of the KSHV latency-associated nuclear antigen and the AP1 response element. Blood 2002; 99: 649-654.

166. Tomita M, Semenza GL, Michiels C, et al. Activation of hypoxia-inducible factor 1 in human T-cell leukaemia virus type 1-infected cell lines and primary adult T-cell leukaemia cells. The Biochemical Journal 2007; 406: 317-323.

167. Cai QL, Knight JS, Verma SC, Zald P, Robertson ES. EC5S ubiquitin complex is recruited by KSHV latent antigen LANA for degradation of the VHL and p53 tumor suppressors. PLoS Pathogens 2006; 2: e116. 